\title{
Effective use of phenyl and heterocyclic rings: Synthesis of inhibitors of HIV-RT and thrombin*
}

\author{
Terry A. Lyle ${ }^{\dagger}$ \\ WP-14-3, Merck Research Laboratories, West Point, PA 19486, USA
}

\begin{abstract}
In two different programs to develop enzyme inhibitors for the treatment of HIV infection and abnormal thrombosis, we have effectively replaced aliphatic groups with pisystems: i.e. acetylenes, aromatic, and heterocyclic rings. This has led to an improvement in both the activity and pharmacokinetic properties of these compounds.
\end{abstract}

\section{INHIBITORS OF HIV REVERSE TRANSCRIPTASE}

\section{Introduction}

Subsequent to the identification of reverse transcriptase (RT) as an essential enzyme in the life-cycle of retroviruses [1], our understanding of its mechanism and role in viral replication has rapidly evolved. This knowledge has become more important in view of the identification of a growing number of retroviral associated diseases, particularly the acquired immunodeficiency syndrome (AIDS). It has been established that AIDS is caused by the human immunodeficiency virus (HIV), and current treatment of HIV infection is dependent upon inhibitors of HIV-RT. Because many of the drugs which have been approved for the treatment of HIV in the U.S. are nucleoside derivatives, they share a common mechanism of action as well as some significant clinical toxicity [2]. A number of laboratories have undertaken the search for RT inhibitors of different structural classes with the goal of introducing better tolerated and more effective therapies. Interest in such compounds has led to the discovery of several novel non-nucleoside HIV-1 RT inhibitors from screening leads [3]. Although the structural diversity among these non-nucleoside RT inhibitors is rather remarkable, most of them share the property of interacting with RT in a non-competitive manner. Additionally, none of these non-nucleosides inhibit HIV-2 RT to any significant extent, lending weight to the hypothesis that these compounds are binding to an allosteric site on HIV-1 RT which is not shared by HIV-2 RT. A number of groups have identified the regions of HIV-2 that impart resistance to non-nucleoside inhibitors [4]. Early results from in-vitro passaging of HIV in the presence of several of these inhibitors, as well as results from initial clinical trials have confirmed that one or two mutations in the RT region of the viral genome can confer substantial resistance [5]. The therapeutic value of the present generation of non-nucleoside inhibitors as single agents is therefore limited. This article describes our effort to identify novel HIV-RT inhibitors that might offer therapeutic value, culminating in the discovery of Efavirenz, the first once-daily medication for the treatment of HIV infection and AIDS.

\section{Lead compounds}

In addition to the pyridinone [6] and indole [7] classes of HIV-1 RT inhibitors that have been disclosed from these laboratories, another structural lead emerged from our screening program and an investigation was initiated using 1 as a lead compound. Initial concerns about the reactivity of the aminal functionality as well as the presence of a thiourea group were addressed by a series of compounds where the ether oxygen was replaced with carbon, and the sulfur atom replaced by oxygen. This tactic provided

\footnotetext{
* Lecture presented at the 4th International Symposium on Functional Dyes-Science and Technology of Functional $\pi$-Electron Systems, Osaka, Japan, 31 May-4 June 1999, pp. 2009-2160.

$\dagger$ Correspondence: E-mail: terry_lyle@merck.com
} 
compounds with good activity against HIV-RT, and were no longer hydrolytically unstable. Structure-activity studies with these compounds also indicated that the enzyme could accommodate a small lipophilic group and a large lipophilic group at the 4-position. As for the lead compound $\mathbf{1}$, phenyl was an effective large group, and among the small groups tested, acetylene was among the best in terms of both potency and oral bioavailability as shown for compound $\mathbf{2}$. However, $\mathbf{2}$ was not optimal, and we therefore searched for other combinations of groups at the 4-position.<smiles>CCOC1(c2ccccc2)c2ccc(Cl)cc2NC(=S)N1C</smiles>

$0.056 \mu \mathrm{M}(\mathrm{rC}-\mathrm{dG})$<smiles>C#CC1(c2ccccc2)c2cc(Cl)ccc2NC(=O)N1C</smiles>

$0.043 \mu \mathrm{M}(\mathrm{rC}-\mathrm{dG})$

\section{Optimization}

The chemistry for the preparation of the 4-phenyl compounds was not generally applicable, so we pursued a new synthesis of 4,4-di-substituted quinazolinones. We proposed that organometallic reagents could be added to intermediates such as $\mathbf{3}$, giving rise to the desired compounds. However, in some cases this intermediate was unstable, and gave rise to an exocyclic tautomer which was unreactive to nucleophiles. In order to prevent this isomerization, we proposed the use of a cyclopropyl group at the 4-position. In practice, this strategy worked well, and allowed the preparation of a variety of 4,4-di-substituted quinazolinones, with or without the presence of an alkyl group at the N-3 nitrogen as was required in the phenyl compounds. With cyclopropyl assuming the role of a small lipophilic group, a variety of large lipophilic groups were introduced at the 4-position. Several of these compounds were very potent enzyme inhibitors as well as suppressing HIV replication in cell culture. However, most of these compounds displayed poor oral bioavailability which was attributed to oxidative metabolism of either the methyl group at N-3 or the alkyl group at C-4. An exception to this metabolic pattern was observed for the acetylenic compound $\mathbf{4}$, which had measurable oral bioavailability. This prompted the exploration of substituted acetylenes at C-4, giving rise to the 2-pyridyl acetylene 5 [8]. In addition to the high activity against HIV-RT, this compound had excellent pharmacokinetic profiles in rhesus monkey and rat, leading to its selection as the development candidate L-738,372. This is an example of how replacing an aliphatic group with an extended pi system can dramatically change the pharmaceutical properties of a compound.

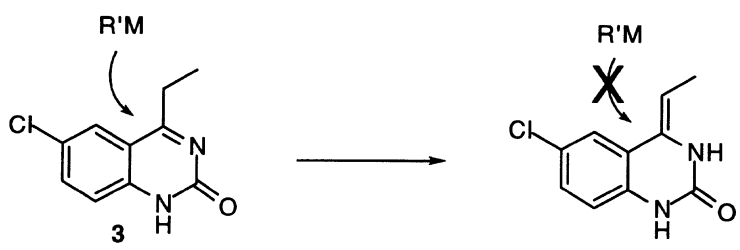<smiles>[Y6]N1C(=O)Nc2ccc(Cl)cc2C1([R7])C1CC1</smiles><smiles>C#CC1(C2CC2)c2ccc(Cl)cc2NC(=O)N1C</smiles><smiles>O=C1Nc2ccc(Cl)cc2[C@]1(C#Cc1ccccn1)C1CC1</smiles> 
A similar approach was taken in the optimization of the related trifluoromethylbenzoxazinone series of inhibitors 6 [9]. Again, replacement of aliphatic groups gave rise to the C-4 cyclopropylacetylenes. These compounds were also very potent enzyme inhibitors, and also provided excellent pharmacokinetic profiles. Resolution provided a second development candidate 7 Efavirenz (L-743,726, DMP-266) which is now marketed in several countries as either Sustiva ${ }^{\mathrm{TM}}$ (Dupont) or Stocrin $^{\mathrm{TM}}$ (Merck). Its superior human pharmacokinetic profile has made it the first once-daily anti-HIV medication for use in combination therapy.<smiles>C=CCCCC1(C)OC(=O)Nc2ccc(Cl)cc21</smiles>

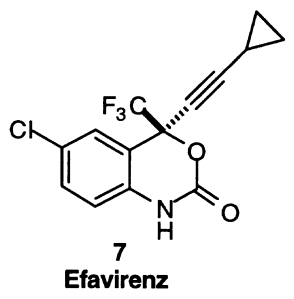

\section{Thrombin inhibitors}

From a survey of the recent literature, it is clear that the discovery of a highly selective, potent, and orally bioavailable inhibitor of the serine protease thrombin is a top priority for many research laboratories throughout the world. The many limitations of approved anticoagulants and those currently in clinical trials are major reasons to develop such an agent [10]. An ideal thrombin inhibitor would provide predictable levels of anticoagulation when administered parenterally or orally, with minimal danger of bleeding or unrelated side effects. A highly selective inhibitor of thrombin that met these criteria would be an attractive candidate for drug development.

One of our initial objectives for an orally active thrombin inhibitor was to achieve as much selectivity as possible over trypsin, an important, closely related digestive enzyme. Recent work from these laboratories has described one approach to achieving substantial trypsin selectivity starting from traditional tripeptide inhibitors. The result of these efforts was the novel inhibitor L-370,518 (8) containing a trans-aminocyclohexylglycine ketoamide residue at the P1 position, traditionally occupied by a lysine or arginine [11].
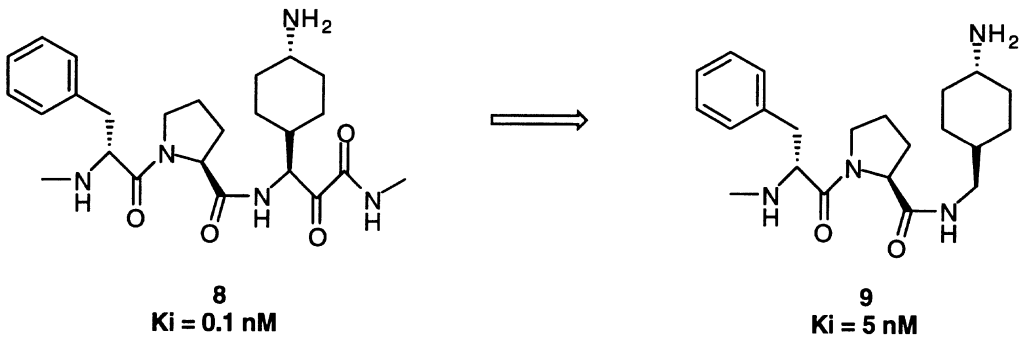

This compound is based upon the well-known D-Phe-Pro-Arg-H prototype in which the basic Arg residue binds to Asp189 in the S1 subsite, the proline ring sits in the S2 subsite, and the phenyl ring of the D-Phe residue occupies the P3 'aryl binding site' of the enzyme. A key interaction is the covalent bond between the electrophilic aldehyde and Ser195 of the enzyme. This type of covalent interaction is utilized in many potent inhibitors of serine proteases, and is commonly found in the D-Phe-Pro-Arg tripeptidetype thrombin inhibitors $[10 \mathrm{a}-\mathrm{c}]$. Many other groups have been employed as electrophiles for the serine hydroxyl (e.g., chloromethyl ketones, $\alpha, \alpha$-difluoroketones, phosphinic acids, and boronic acids) [10]. Compound $\mathbf{8}$ utilizes a primary amine as the basic group to interact with Asp189, and an $\alpha$-ketoamide as the Ser195 electrophile. The side chain at the S1 site was designed to take advantage of the difference in the steric electrostatic environments of the 'selectivity pockets' of thrombin and trypsin, resulting in an inhibitor with a $\mathrm{K}_{\mathrm{i}}$ of $90 \mathrm{pM}$ for thrombin, and $1.15 \mu \mathrm{M}$ for trypsin [11]. This 13000 -fold improvement in selectivity over the corresponding acyclic analogs [12] was an important step in our search for a clinical candidate. 
A second major advance was the discovery that elimination of the electrophilic ketoamide group to give compound 9 did not result in complete loss of inhibition [13]. However, even after extensive optimization of this new series of dipeptide based inhibitors, sufficient oral bioavailability and plasma half-life remained elusive.

The next significant improvement in oral bioavailability was achieved by replacing the highly basic aminocyclohexyl group with less basic heterocyclic amines. In particular, compounds containing a 2aminopyridine, as illustrated by compound 10, proved to have an excellent fit in the P1 pocket of thrombin. In addition, these compounds displayed much improved pharmacokinetics [14]. However, all efforts to improve upon the intrinsic potency of $\mathbf{1 0}$ caused significant losses in bioavailability and duration of action.

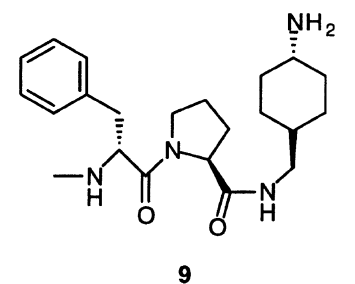

$\mathbf{K i}=\mathbf{5} \mathbf{n M}$

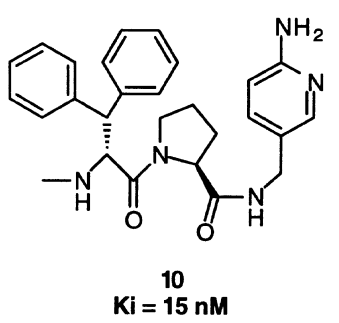

$\mathrm{Ki}=15 \mathrm{nM}$

More progress in the oral bioavailability area was based on work done by workers at Zeneca who had successfully replaced the proline residue in their elastase inhibitors with either a pyridinone or a pyrimidinone ring [15]. Application of this principle to thrombin led to the pyridinone containing compound 11. This compound is the first example of a sub-nanomolar, achiral, efficacious thrombin inhibitor [16]. Further refinement of this series of compounds by utilizing the aminopyridine P1 group gave compounds (i.e. 12) that now displayed good oral bioavailability [17].

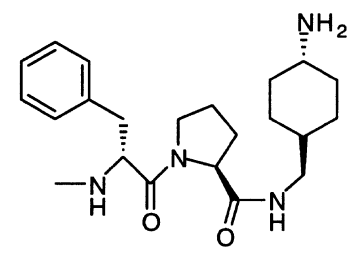

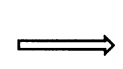

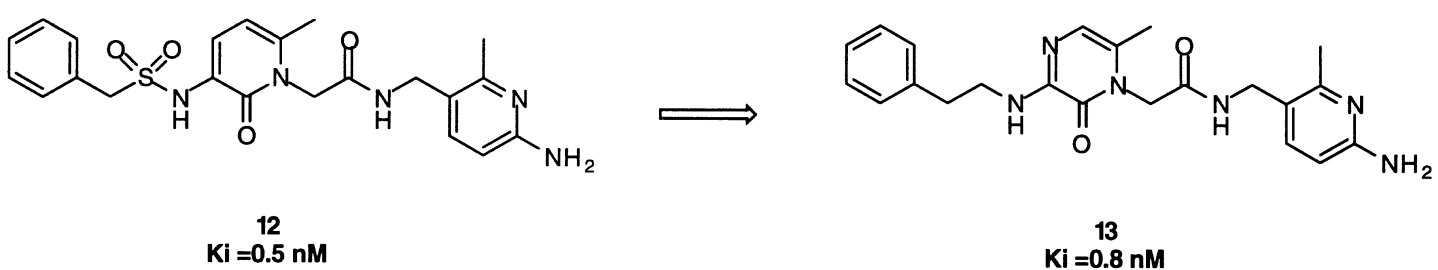<smiles>Cc1ccc(NS(=O)(=O)Cc2ccccc2)c(=O)n1CC(=O)NCC1CCN(C(=N)N)CC1</smiles>

$\mathrm{Ki}=0.5 \mathrm{nM}$

Finally, in order to improve upon the duration of action for these compounds, the benzylsulfonamideopyridinone was modified to give the phenethylaminopyrazinone $\mathbf{1 3}$ which meets almost all of the requirements for an oral thrombin inhibitor [18]. This then represents a second example of where replacing the primarily aliphatic structures found in the lead compounds with aromatic and heteroaromatic groups has led to a significant improvement overall.

\section{CONCLUSION}

The work described above exemplifies the positive impact that incorporation of pi-systems as replacements for aliphatic functionality can have in pharmaceutical research. This effect can be attributed to changes in physical properties which bring about improvements in absorption and metabolism. 


\section{REFERENCES}

1 D. Baltimore. FASEB J. 9, 1660 (1995).

2 D. D. Richman, M. A. Fischl, M. H. Grieco, M. S. Gottlieb, P. A. Volberding, O. L. Laskin, J. M. Leedom, J. E. Groopman, D. Mildvan, M. S. Hirsh, G. Jackson, D. T. Durack, S. Nusinoff-Lehrman. New Engl. J. Med. 317, 192 (1987).

3 (a) S. D. Young. Perspect. Drug Discovery and Des. 1, 181 (1993). (b) D. Romero. Annual Rep. Med. Chem. 29, 123 (1994).

4 C-K. Shih, J. M. Rose, G. L. Hansen, J. C. Wu, A. Bacolla, J. A. Griffin. Proc. Natl. Acad. Sci. USA 88(21), 9878 (1991).

5 (a) J. H. Nunberg, W. A. Schleif, E. J. Boots, J. A. O’Brien, J. C. Quintero, J. M. Hoffman, E. A. Emini, M. E. Goldman. J. Virol. 65, 4887 (1991). (b) V. V. Sardana, E. A. Emini, L. Gotlib, D. J. Graham, D. W. Lineberger, W. Long, A. J. Schlabach, J. A. Wolfgang, J. H. Condra. J. Biol. Chem. 267, 17526 (1992).

6 M. Goldman, J. Nunberg, J. O’Brien, J. Quintero, W. Schleif, K. Freund, S. Gaul, W. Saari, J. Wai, J. Hoffman, P. Anderson, D. Hupe, E. Emini, A. Stern. Proc. Natl. Acad. Sci. USA 88, 6863 (1991).

7 T. M. Williams, T. M. Ciccarone, S. C. MacTough, C. S. Rooney, S. K. Balani, J. H. Condra, E. A. Emini, M. E. Goldman, W. J. Greenlee, J. A. O’Brien, V. V. Sardana, W. A. Schlief, A. D. Theoharides, P. S. Anderson. J. Med. Chem. 36, 1291 (1993).

8 T. J. Tucker, T. A. Lyle, C. M. Wiscount, S. F. Britcher, S. D. Young, W. M. Sanders, W. C. Lumma, M. E. Goldman, J. A. O’Brien, R. G. Ball, C. F. Homnick, W. A. Schleif, E. A. Emini, J. R. Huff, P. S. Anderson. J. Med. Chem. 37, 2436 (1994).

9 S. D. Young, S. F. Britcher, L. O. Tran, L. S. Payne, W. C. Lumma, T. A. Lyle, J. R. Huff, P. S. Anderson, D. B. Olsen, S. S. Carroll, D. J. Pettibone, J. A. O’Brien, R. G. Ball, S. K. Balani, J. H. Linn, I-W. Chen, W. A. Schleif, V. V. Sardana, W. J. Long, V. W. Byrnes, E. A. Emini. Antimicrob. Agents Chemother. 39, 2602 (1995).

10 (a) C. Tapparelli, R. Metternich, C. Ehrhardt, N. S. Cook. Trends Pharmacol. Sci. 14, 366 (1993). (b) T. A. Lyle. Perspect. Drug Discovery Des. 1, 453 (1993), and references sited therein. (c) W. Bode, I. Mayer, U. Baumann, R. Huber, R. S. Stone, J. Hofsteenge. EMBO J. 8, 3417 (1989).

11 S. F. Brady, S. D. Lewis, C. D. Colton, K. J. Stauffer, J. T. Sisko, A. S. Ng, C. F. Homnick, M. J. Bogusky, J. A. Shafer, D. F. Veber, R. F. Nutt. Pept.: Chem., Struct. Biol., Proc. 14th, Am. Pept. Symp. 1995 331-333 (1996).

12 S. F. Brady, J. T. Sisko, K. J. Stauffer, C. D. Colton, H. Qiu, S. D. Lewis, A. S. Ng, J. A. Schafer, M. J. Bogusky, D. F. Veber, R. F. Nutt. Bioorg. Med. Chem. 3, 1063 (1995).

13 T. A. Lyle, Z. Chen, S. D. Appleby, R. M. Freidinger, S. J. Gardell, S. D. Lewis, Y. Li, E. A. Lyle, J. J. Lynch Jr., A. M. Mulichak, A. S. Ng, A. M. Naylor-Olsen, W. M. Sanders. Bioorg. Med. Chem. Lett. 7, 67 (1997).

14 D. M. Feng, S. J. Gardell, S. D. Lewis, M. G. Bock, Z. Chen, R. M. Freidinger, A. M. Naylor-Olsen, H. G. Ramjit, R. Woltmann, E. P. Baskin, J. J. Lynch, R. Lucas, J. A. Shafer, K. B. Dancheck, I-W. Chen, S-S. Mao, J. A. Krueger, T. R. Hare, A. M. Mulichak, J. P. Vacca. J. Med. Chem. 40, 3726 (1997).

15 F. J. Brown, D. W. Andisik, P. R. Bernstein, C. B. Bryant, C. Ceccarelli, J. R. Damewood Jr., P. D. Edwards, R. A. Earley, S. Feeney. J. Med. Chem. 37, 1259 (1994).

16 P. E. J. Sanderson, D. L. Dyer, A. M. Naylor-Olson, J. P. Vacca, S. J. Gardell, S. D. Lewis, B. J. Lucas, E. A. Lyle, J. J. Lynch Jr., A. M. Mulichak. Bioorg. Med. Chem. Lett. 7, 1497 (1997).

17 P. E. J. Sanderson, K. J. Cutrona, B. D. Dorsey, D. L. Dyer, C. M. McDonough, A. M. Naylor-Olsen, I-W. Chen, Z. Chen, J. J. Cook, S. J. Gardell, J. A. Krueger, S. D. Lewis, J. H. Linn, B. J. Lucas, E. A. Lyle, J. J. Lynch Jr., M. T. Stranieri, K. Vastag, J. A. Shafer, J. P. Vacca. Bioorg. Med. Chem. Lett. 8, 817 (1998).

18 P. E. J. Sanderson, T. A. Lyle, K. J. Cutrona, D. L. Dyer, B. D. Dorsey, C. M. McDonough, A. M. Naylor-Olsen, I-W. Chen, Z. Chen, J. J. Cook, C. M. Cooper, S. J. Gardell, T. R. Hare, J. A. Krueger, S. D. Lewis, J. H. Linn, B. J. Lucas, E. A. Lyle, J. J. Lynch Jr., M. T. Stranieri, K. Vastag, Y. Yan, J. A. Shafer, J. P. Vacca. J. Med. Chem. 41, 4466 (1998). 